\title{
Modelling the economic impacts of a large event: The case of the Gold Coast 2018 Commonwealth Games
}

\author{
Tien Pham, Susanne Becken and Michael Powell \\ t.pham@griffith.edu.au, \\ s.becken@griffith.edu.au and \\ m.powell@griffith.edu.au
}

\begin{abstract}
This article consolidates the pros and cons of the two common modelling techniques for economic impact analysis: the input-output multiplier and the computable general equilibrium (CGE) technique. The latter is recommended for large event assessment and was used to examine the economic impacts of the Gold Coast 2018 Commonwealth Games. The Games is estimated to have generated approximately $\mathrm{A} \$ 2.5$ billion of gross state product (GSP) to Queensland after netting out the costs incurred. The effect is spread over a period of nine years from pre-Games period of preparation for the Games, through the Games period itself, and then rather significantly in the post-Games period. While benefits accrue to Queensland, the rest of Australia is estimated to lose due to the so-called 'crowding out effect'.
\end{abstract}

\section{Introduction}

Events are increasingly becoming an important means for tourism destinations or countries to stimulate economic activity by attracting tourists from within the country as well as from overseas to generate tourism revenue. While small and perhaps medium-sized events demand smaller budgets, mainly for the operational costs, large events such as the Olympic Games or the Commonwealth Games, which involve participants from more than 70 countries, will require additional expensive capital construction for new infrastructure. These include, for example, a Games village for contestants to stay in during the event, sport stadiums or venues for the various types of competitions that form part of the event schedule and perhaps additional transport infrastructure. The construction cost can be very significant: such new infrastructure will generally require government or public expenditure over and beyond that required if no such event were planned. It is thus expected that the host country 


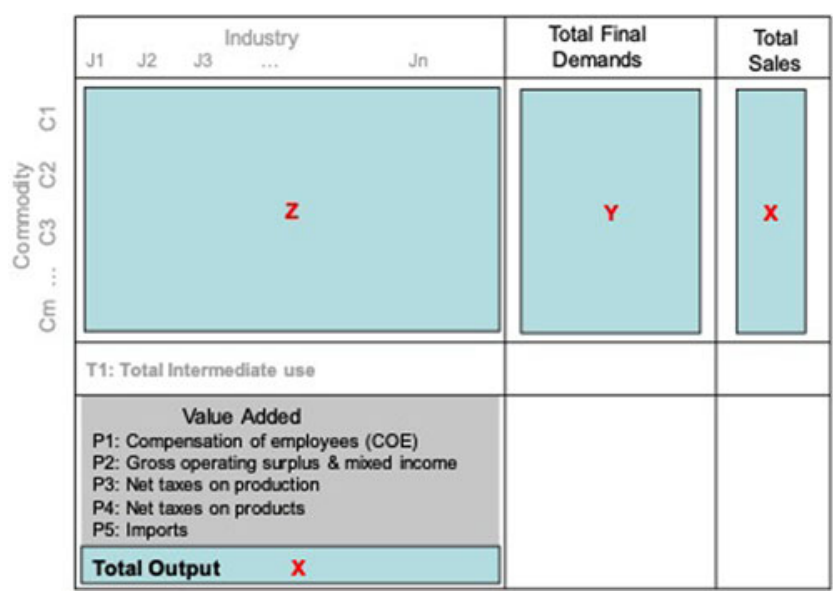

Figure 1

A representation of an 10 table.

In Figure 1: X: a vector of industries' output, representing both total costs (column sums) and total sales (row sums) of industries. Z: a matrix of intermediate inputs used by industries to produce output $X$. If the technology is not changing, then the amount of intermediate inputs can be derived using a fixed proportion of the individual inputs in total output. In this case, $Z$ can be expressed as: $Z=A^{\star} X$, where $A$ is an input share matrix, or also referred to as a coefficient matrix. $Y$ : a representative vector of total final demand to simplify the presentation. Actual final demands in 10 tables include household consumption, investment, government consumption and exports. The size of an economy is reflected in the Value Added section, which excludes values of intermediate inputs to avoid double counting. Gross Value Added $(G V A)=P 1+P 2+P 3$. Gross Domestic Product (GDP) from the income side $=$ GVA + P4. Gross Domestic Product from the expenditure side $=\mathrm{Y}-\mathrm{P} 5$.

will need to quantify, or model, the impacts of the Games to justify increased public sector expenditure and provide some measure of the return on investment.

Modelling techniques for economic impact assessment of events vary, depending primarily on the objectives sought as well as the size of the individual events. The range of techniques includes input-output (IO) multipliers, computable general equilibrium (CGE) modelling and cost benefit analysis (CBA). Each approach has its own strengths and limitations, and each is associated with different types of challenges for the modellers as well as for readers in terms of interpretation of findings.

By nature, CBA analysis is very different from the IO and CGE modelling techniques. Its primary focus is on quantifying the externalities or social utility (Barget and Gouguet 2010; Taks et al. 2014) that are not represented directly by the expenditure of visitors and the infrastructure development made by the host organisation. Although CBA analysis is not an essential part of economic impact modelling, it is used occasionally to complement the economic impact assessment and provide further justification decisions about using public funds.

IO multipliers and CGE modelling are used to estimate the economic impacts of all market transactions related to events. In principle, the assessments need to 
capture the interaction among industries in an economy, given the broad range of inputs required by the event. This is particularly important for large (or mega) events, due to their scale. These modelling techniques are based on an input-output database. While the IO modelling technique is relatively easy to implement, it has unrealistic assumptions of no price effects and no resource constraints. Results of its application tend to represent over-estimates of the actual event impact, as pointed out in the literature (Barget and Gouguet 2010; Brisassoulis 1991; Crompton 1995; Dwyer, Forsyth and Spurr 2006; Matheson 2009; Taks et al. 2014).

The CGE modelling technique improves on the unrealistic assumptions of the IO analysis by explicitly recognising changes in relative prices, which are used to reallocate the constrained resources among industries in response to the shocks or stimulus (events) to the economy caused by the event. In the process, some industries will benefit from a positive shock but others could be adversely affected. The downside of CGE modelling is that it is data intensive and is not always suitable for small events. For more details on the pros and cons of CGE modelling, please refer to the established literature (e.g. Dwyer, Forsyth and Spurr 2004, 2006). In particular, Massiani (2018) provides a comprehensive review of the promises and compromises of the CGE modelling technique as a tool for assessing economic impacts of events.

The objective of this article is not to justify the decision to host the Gold Coast 2018 Commonwealth Games. After a discussion of the pros and cons of the IO and CGE approaches, the article will focus mainly on the approach actually used to assess the economic impacts of the Gold Coast 2018 Games. Given the fact that there are still examples of medium and large events using IO multipliers in recent times, this article once again reiterates and rationalises the choice of modelling the economic impacts of a large event explicitly. It then demonstrates how events are assessed using a CGE model, with the Gold Coast 2018 Games as the example. Although the article is set in the context of the Gold Coast in regional Australia, it is applicable to regions in other countries.

\section{Why 10 analysis often over-estimates economic impacts}

The creation of the IO table (Leontief, 1936) was a quantum leap in the way how we account for the size of an economy and its interdependent industries. Fundamentally, the IO table is a snapshot of an economy over one period, which brings together both the demand and supply sides, not only at the macro level but also at the industry level (Figure 1). The IO table has been incorporated into the core System of National Account (SNA) across all countries since then, and has become an integral part of economic planning for many countries. It has also inspired largescale CGE for more than several decades.

Contribution of industries to an economy are thus captured by their values of GVA and GDP in the total. At the industry level, it is argued that GVA is a better measure to compare industry contribution to an economy, as it is directly related to the production activity of industries, and free of the distortion created by the net taxes on products imposed by the government.

The IO table is used to derive multipliers that can be applied in an economic impact analysis to estimate the required output level of industries for a given change 
in final demands. This could be an increase in exports or household consumption. The form of IO multipliers can be developed and expressed as follows.

$$
\begin{gathered}
\mathrm{X}=\mathrm{Z}+\mathrm{Y} \\
\mathrm{X}=\mathrm{A} * \mathrm{X}+\mathrm{Y} \\
(\mathrm{I}-\mathrm{A}) * \mathrm{X}=\mathrm{Y} \\
\mathrm{X}=(\mathrm{I}-\mathrm{A})^{-1} * \mathrm{Y}
\end{gathered}
$$

Equation (1) simply states that the total output of an industry is the sum of all the output sales to other industries as intermediate usage and sales to final demands in the economy, such as household consumption, government consumption or even exports. Equation (2) is an alternative of (1) by expressing the intermediate values in the form of the input shares (matrix A) and its corresponding output level. Equations (3) and (4) are just mathematical rearrangements to represent the output vector as a function of final demands $(\mathrm{Y})$ and the input share matrix (A).

Equation (4) is indeed a representation of the so-called IO multipliers, which are applied in economic impact analysis to estimate the new level of output for a given change in $\mathrm{Y}$. While the IO tables are of great use from the national account perspective, IO analysis seems to inherit conceptual challenges for the economic impact assessment, as it assumes no price effects on demands for goods and service; cross-price and ownprice elasticities are irrelevant in equation (4). Changes in demands will not affect price level in the economy, and vice versa. Furthermore, this does not take into account resource constraints within an economy. Labour and capital (GVA) are not part of the production function (equation (4)), so changes in industry output are not governed by resource availability. Industries will not need to compete with each other for resources, which means there will be no crowding-out effects on any industries when one industry expands its output in response to higher demands.

For small events, the assumption of no resource constraints may be justifiable in the context that resources at the national level might be deemed abundant for such an event. Such small events are often associated with small regions and funded by local governments, without state and federal governments being directly responsible for such activities, and local governments typically do not have the power to influence movements of resources. In that situation, it might not be plausible to assume that labour and capital from the far side of the country would be readily relocated to a small host region. Use of IO multipliers in this case depends on the specific context of the event itself and its location. Nevertheless, for large events, which require substantial resources from the preparation before the event to the operational time of the event, the above limitations are certainly the main reason for results of IO analysis to be over-estimated compared with the real impact of the event. For large events such as the Commonwealth Games, resources such as capital 
and labour are mobilised to the host region or city by the state and federal governments or by the attraction of job opportunities.

\section{The CGE framework}

A typical CGE model comprises an IO database with producing industries (supply) and final users (demand). The industries employ workers and acquire capital and intermediate inputs in their production process to produce goods and services, which are then purchased by final users such as household consumption, investment, government consumption and exports. Both supply and demand are governed by optimisation theory, using the functional form of a constant elasticity of substitution (CES). The essence of this functional form allows users in the model to source goods and services from a cheaper origin among all available supplies of similar goods and services - for example, domestic versus imported sources. Producers will particularly choose their input mix to minimise their production costs for a given market price of their output, and the household sector will select a consumption bundle to maximise its 'satisfaction'1 at a given level of income.

An algebraic representation of a CGE model can be specified as:

$$
F\left[\left(X_{1}\right),\left(X_{2}\right)\right]=0
$$

where $X_{1}$ is a vector of $\mathrm{n}$ variables endogenously determined by a set of $\mathrm{n}$ differentiable equations $F($.$) and X_{2}$ is another vector of $\mathrm{m}$ variables that are exogenous to the equation system.

Typically, the $F($.$) equation system describes:$

- demands for goods and services by industries, investment, household, government and exports

- explicit demands for capital, labour and land by industry, thus CGE models are explicitly subject to resource constraints

- total production costs of industries

- market clearing conditions for supply and demand (total output equal total sales for each industry)

- market prices that users pay with explicit components of industry production costs, government net taxes, import costs and add-on costs such as transportation and retail margins (Dixon et al., 1982).

\section{Model closures}

As the model contains more variables than the number of equations, the choice of setting variables in the two endogenous and exogenous sets reflects the implied timeframe of a scenario, and affect results of the simulations.

In a short-run scenario, often real wages are assumed to be rigid while changes in employment will determine the final outcome of the unemployment in the labour market. In contrast, in a long-run scenario, it is assumed that whoever would like a job will get a job, provided that they are willing to accept the prevailing wage rates that industries can offer. The long-run scenario thus often reflects a full employment level with flexible real wage rates. 
For the capital market, a short-run scenario implies a fixed capital stock level, as capital stocks need time to be built up. In that case, the rates of returns to capital become endogenous to settle the capital market. In the long run, capital stocks are attracted to and built up in prospering industries only, and the flow of capital will continue as long as the rates of return in these industries are higher than the pre-shock level. In contrast, industries with adverse impacts of a shock will experience a decline in their capital stock until the rates of return are brought back to the pre-shock level. As such, the long-run scenario will result in constant rates of return and changeable (endogenous) capital stocks. CGE models have previously been used in the context of tourism (Madden 2002, 2006; Meng and Pham 2017; Pham et al. 2015; Pham, Nghiem and Dwyer 2017) and events (Giessecke and Madden 2007; Li, Blake and Cooper 2011) and is the most appropriate approach for estimating the impact of a large event such as the Commonwealth Games, which was expected to attract a significant number of participants, spectators and tourists.

\section{Database modifications}

The model used in this case is developed from an existing regional CGE base model, the so-called TERM model (Horridge, Madden and Wittwer 2005). The version of the model used in this analysis contains four regions: the Gold Coast, Brisbane, the rest of Queensland, and the rest of Australia. ${ }^{2}$ As a typical IO table, the TERM database does not have tourism consumption explicitly represented in the model. Consumptions of domestic tourists and household are combined in household consumption; similarly, expenditure of inbound visitors is embedded in exports demand. Hence, the impacts of tourism on household consumption and exports cannot be captured accurately.

For events such as the Commonwealth Games, however, it is imperative to have tourism separated from those final demands for impact assessment on the household sector so that it can be measured accurately. Consequently, for the purpose of targeting specific tourism markets related to the Games, the TERM database is augmented to capture both inbound and domestic sectors - hereafter TERMTOUR - with the tourism consumption separated out from the original final demands. After this modification, the inbound sector covers the top ten individual markets of Australia, and the domestic sector comprises bilateral flows of overnight visitors for all regions. A description of the full process of developing the TERMTOUR database is not within the scope of this article, but a similar procedure can be found in Pham, Simmons and Spurr (2010) and Pham, Xin and colleagues (2017).

The second modification to the database is the incorporation of expenditure related to the event - that is, the Gold Coast Commonwealth Games in this present study - that was originally captured in as a corporate balance sheet. The most relevant data from the balance sheet for the IO modification are the operational expenses and the sales revenue from the Games. These include ticket sales, broadcast rights, sponsorship and merchandise (e.g. mascots, branded clothing, etc.). The total sales are treated as the output of a newly created industry, the Commonwealth Games Industry (CGI). As the total cost of putting on the Games is larger than the output (the sum of all sales revenue), the difference is treated as a subsidy provided to the CGI mainly by the Queensland Government in order to 


\begin{tabular}{lc}
\hline Table 1 Cost and sales structure of the Commonwealth Games industry \\
\hline & Values \\
\hline Total output & 216.0 \\
Operational expenses & 1080.3 \\
Subsidy & -864.2 \\
Total sales & 216.0 \\
Broadcast rights & 65.4 \\
Sponsorship & 81.7 \\
Ticket sales & 65.9 \\
Licensing/merchandising & 2.8 \\
Mascot & 0.2 \\
\hline
\end{tabular}

Source: Office of the Commonwealth Games (2018b).

have costs and sales of the CGI sector in the IO database balanced. As will be seen, the subsidy is financed partially from the revenue of net taxes in the Games year and partially by an assumption of budget neutrality in the post-Games year period.

The value of the operating expenses in Table 1 is at the aggregate level. Actual expenses include a wide range of goods and services that are mapped directly onto the commodity set of the TERM-TOUR model.

In conjunction with the sales side of CGI, the ticket sales component is identified by different types of visitors, and each of them is fully elaborated to include specific expenditure patterns of corresponding visitors from domestic regions and inbound international markets (e.g. from the United Kingdom, Hong Kong, Singapore and New Zealand). These values of ticket sales represent the connection between the CGI and revenue of all of these additional visitors that the Commonwealth Games generates in the Gold Coast region.

Although the operation of the CGI and the associated tourism expenditure are in the order of hundreds of millions of Australian dollars, they are uniformly scaled to a single unit of output and embedded in the TERM-TOUR database. In this way, the inclusion of the new Games expenditure does not change the integrity of the original database, particularly the gross regional product (GRP) of the Gold Coast - the host region. During simulations, all values in this skeleton structure are 'shocked' to increase to the actual level in order to estimate the flow-on impacts of the Commonwealth Games on the domestic economy. This feature of the database is used during the Games year only, to reflect the short-term nature of the Games. In contrast, the existence of specific inbound markets and the bilateral flows of tourism between regions described previously are used to simulate tourism impacts on the regional economies, mainly in the periods before and after the Games year. This is explained further below.

\section{Simulation set-ups}

The Commonwealth Games itself only lasted for twelve days, from 4-15 April 2018; however, the preparation prior to the Games and the legacy after the Games are modelled over a nine-year period. For the purpose of this model, the whole timeframe is classified into three main periods, reflecting the nature of the associated 


\begin{tabular}{lc}
\hline Table 2 A typical pre-Games year summary of expenditure \\
\hline Pre-games years & \$ million \\
\hline Construction & \\
total investment & 283.4 \\
Re-prioritising transfer & -169.8 \\
Tourism expenditure & 17.3 \\
Net stimulus & 130.9 \\
\hline
\end{tabular}

Source: Office of the Commonwealth Games (2018b).

activity in each period: four years pre-Games, the Games year itself, and four years post-Games.

\section{Pre-Games sim (2013-14 to 2016-17)}

As the model is simulated in a comparative static mode, the data presented in Table 2 are on an annual average basis, referred to as a typical year. This pre-Games period is characterised by the construction and development of the Games Village and stadiums (including the upgrade of existing infrastructure). The estimated actual construction costs of the construction per year was $\$ 283.4$ million, as presented in Table 2. The total construction cost was contributed by both private and public sectors. The contribution of the public sector was assumed to be offset by an equivalent transfer from other activity in the Queensland Government budget to give priority to the Games, as represented by the amount of $-\$ 169.8$ million each year. It is calculated in such a way that the costs of infrastructure development will not affect the government budget position by the end of the pre-Games year.

The amount of tourism expenditure in Table 2 includes the expenditure of some contestants who actually visited the Gold Coast city prior to the Games in order to become familiar with the weather and equipment before the competition. As advised by an expert panel, the Games would induce a small number of visitors to come the region in the pre-Games period (Pham, Xin et al. 2017); hence, their expenditure is also included in the total tourism expenditure presented in Table 2.

\section{Games year (2017-18)}

Stimuli in the Games year are mainly from the Games operation and visitor expenditure during their visits to the event. Table 3 provides an estimated actual amount of total operational costs and revenue of the Games.

Data for tourism expenditure were released in the GC2018 Visitor Study by the Office of the Commonwealth Games (2018a), Department of Innovation, Tourism Industry Development and the Commonwealth Games. The data were collated from a survey of 13,780 attendees across three main groups of visitors - spectators, volunteers and media - during the Games period, and are used in this model.

An interesting finding from DSpark (2018), which captures movements of people through mobile phone data, was the magnitude of the 'time-switching' effect of local residents. This effect has been identified in literature (Dwyer, Forsyth and Spurr 2006) but has never been quantified previously. Using mobile data signals, DSpark captures movements of local residents before and during the Games time to identify the (net) number of people, compared with a base case scenario, who left the Gold 
Table 3 Games-year summary of expenditure

\begin{tabular}{lc}
\hline Games year & \$ million \\
\hline Total operational expenses & 1080.3 \\
Tourism expenditure & 561.9 \\
Time switching* & -7.3 \\
Net stimulus & $1,634.9$ \\
\hline
\end{tabular}

Source: Office of the Commonwealth Games (2018b).

*Derived from DSpark (2018).

Coast during the Games. Applying an average spend per day of $\$ 180^{3}$ and the number of days provided by DSpark, the time-switching effect on the local economy is estimated in this article to be approximately $\$ 7.3$ million at current prices in reduced local expenditure by local residents who went elsewhere during the Games period. This reduces the overall expenditure impact during the Games.

\section{Post-Games (2018-19 to 2021-22)}

Data for the post-Games period exhibit the important role that large events such as the Commonwealth Games can play in boosting the local economy in the long run. The key to a successful Games lies in this post-Games period.

Alongside the Commonwealth Games, the Queensland Government also ran a Trade 2018 Program using the Commonwealth Games as a catalyst to promote trade and investment for the state. A survey of participants in the program was used to obtain the likelihood of future induced exports and their associated values. Induced exports were also supplemented using the ratio of advertising cost and expected export sales applied to a wide range of international businesses (Pham, Xin et al. 2017). Both indicate a total of induced exports of $\$ 174.8$ million per year during the post-Games period.

Data from Trade and Investment Queensland show that there was a total of $\$ 41$ million (current prices) of inflow investment following Games-driven business migration to the Gold Coast region. Although this happened before the Games, it is grouped together with other benefits that can be classified as the Games legacy in the post-Games period. This amount is assumed to spread across Brisbane and the Gold Coast in industries directly related to the tourism industry, namely retail trade, accommodation and restaurant.

An important driver of growth in the post-Games period for the Gold Coast, and equally important for Brisbane, is the commitment to maximising the investment return of Games venues in these cities. For this article, considerable additional data became available after the Games on new national and international events secured as a result of the Games from Tourism and Events Queensland, City of Gold Coast and other venue owners and operators. Analysis of this data indicates there could be approximately an additional 250,000 visitor nights from overseas and interstate visitors per year over the four years of the post-Games period. The success of attracting future sports events is a fruitful outcome of a partnership of different departments and organisations at local, state and federal levels, particularly Tourism and Events Queensland, Tourism Australia, City of Gold Coast and Destination Gold Coast. Among the prominent events already drawn to the Gold 


\begin{tabular}{lc}
\hline Table 4 A typical post-Games year summary of expenditure & \\
\hline Category & $\$$ million \\
\hline Exports & 174.8 \\
Investment & 41.0 \\
Village Roadshow Soundstage (new) & 90.3 \\
Tourism expenditure & 206.9 \\
Re-prioritising transfer & -110.0 \\
Net stimulus & 403.0 \\
\hline
\end{tabular}

Source: Office of the Commonwealth Games (2018b).

Coast are Gymnastics Australia's largest ever event, the Gymnastics National Club Carnival (2018), and the world's leading sports convention, the SportAccord World Sport and Business Summit (2019).

Apart from the above sporting events, business events will contribute to the growing event venue utilisation. The Gold Coast has been successful in attracting business delegations from around the world to visit in the post-Games period. It was reported earlier this year that the Gold Coast would host at least 22,450 business delegates in the post-Games years. ${ }^{4}$ In fact, it is expected that the number of delegates will increase as the planned events draw closer. Tourism revenue from venue utilisation for both sport and business activities is estimated to be $\$ 206.9$ million per year at current prices.

In addition to the tourism revenue, Games facilities were also used for film production - for example, for Thor and Aquaman. It is estimated that the revenue from utilising Games facilities for this type of activity will continue to generate approximately $\$ 90$ million per year.

Table 1 reported an amount of $\$ 864.2$ million in support provided by the Queensland Government to the operation of the Commonwealth Games. Our assumption is that this amount is funded as much as possible from the total tax revenue received by the Queensland Government during the pre-Games years and the Games year. The remaining amount of subsidy to be funded at the end of the Games year was estimated to be $\$ 390$ million. To continue funding this, the modelling assumed that the government had obtained a short-term loan to pay off this $\$ 390$ million at the end of the Games year. The government would then have to reduce consumption in each year in the post-Games period to repay this loan with interest, which is approximately $\$ 110$ million per year, as seen in Table 4. By the end of the post-Games period, government budget regarding the funding for the Commonwealth Games returns to a neutral position. Taking everything into account, every year in the post-Games period should generate approximately $\$ 403$ million for Queensland, mainly in the Gold Coast area.

\section{Simulation results}

\section{Pre-Games period (2013-14 to 2016-17)}

Apart from the standard set-up described earlier, the long-run closure in this simulation is modified slightly to allow unemployment rates of the state to respond 


\begin{tabular}{|c|c|c|c|c|}
\hline & $\%$ change & Queensland & Rest of Australia & Australia \\
\hline 1 & Real HH consumption & 0.040 & -0.002 & 0.006 \\
\hline 2 & Real investment & 0.009 & -0.006 & -0.003 \\
\hline 3 & Real GOV consumption & 0.179 & 0.000 & 0.036 \\
\hline 4 & Real exports & -0.032 & -0.016 & -0.018 \\
\hline 5 & Real imports & 0.032 & -0.002 & 0.005 \\
\hline 6 & Real GSP/GDP & 0.036 & -0.004 & 0.003 \\
\hline 7 & Employment & 0.038 & -0.005 & 0.004 \\
\hline 8 & Real wage & 0.005 & 0.002 & 0.003 \\
\hline 9 & Real capital stocks & 0.040 & -0.005 & 0.003 \\
\hline \multirow[t]{2}{*}{10} & Exchange rate & & & -0.010 \\
\hline & Cumulative nominal a & $t$ prices, $\$ m$ & & \\
\hline 11 & Gross state product & 494 & -243 & 251 \\
\hline
\end{tabular}

to the labour demand so that the real wage rates only adjust halfway to what they would be in the standard long-run closure (New South Wales Treasury, 1997). This assumption is based on the fact that the level of unemployment started rising in June 2009 (Australian Bureau of Statistics, hereafter ABS 2018). Thus it is very likely that all the construction developments would help to alleviate the rising unemployment rates in Queensland. The implication is that real wage rates do not have to increase to their full extent.

It is also assumed that government consumption is fixed throughout all states, except for some specific industries in Queensland where the state government invests in capital infrastructure as well as the matching re-prioritisation transfer for the purpose of maintaining budget neutrality.

Table 5 shows typical year results for selected macro variables for Queensland and Australia. During the preparation years, government consumption is estimated to grow 0.179 per cent and is the main driver of the state economy (row 3, Table 5). This reflects an increase in government demand for the construction of Games infrastructure. The development increases real wages and employment in the state (rows 7 and 8, Table 5), which stimulates household consumption in Queensland slightly, at 0.04 per cent.

The increase in the domestic absorption (household consumption, government consumption and investment) makes the domestic currency appreciate by 0.01 per cent (row 10). The exchange rate variable is measured as a ratio of the domestic currency to the aggregate foreign currency. Although it is only a small change, a decline in the ratio means that it requires a smaller amount of the Australian dollars to obtain the same unit of the foreign currency — an appreciation of the Australian dollar. This appreciation is estimated to have adverse impacts on exports from the state, as goods and services produced domestically become more expensive for overseas consumers. Exports from the state are estimated to decline by 0.03 per cent per year. In contrast, the appreciation makes goods and services produced overseas relatively cheaper, hence increasing the import volume of the state by 0.03 per cent. Part of this increase in imports is by the household sector and investment. 
Table 6 Employment effects of a typical pre-Games year (FTEs)

\begin{tabular}{cccc}
\hline & Queensland & Rest of Australia & Australia \\
\hline Pre-games years & 887 & -349 & 538 \\
\hline
\end{tabular}

For the rest of Australia (ROA), the far-reaching impacts on the real wage rates ( 0.002 per cent) and employment $(-0.005$ per cent) are much smaller. The combined effect of both the real wage rates and employment generates a decline in wage income for ROA. It is also affected by the appreciation of the exchange rate, which subsequently reduces overseas exports by -0.016 per cent. This is the highest among all adverse impacts on the ROA's economy. This drop subsequently adds to a reduction in income, and hence household consumption (row 1). Consequently, the economy of ROA contracts marginally by 0.004 per cent per year.

Row 11 of Table 5 provides total sums of cumulative changes in GSP for Queensland and ROA, and GDP for Australia over the whole pre-Games period. While Queensland's economy increases marginally in the pre-Games years (\$494 million), ROA experiences an adverse impact resulting in a marginal decline by nearly half of the increase in Queensland ( $\$ 243$ million). The net impact at the national level is only $\$ 251$ million of GDP. The stimulus of $\$ 130.9$ million in a typical year in the pre-Games period (Table 2) implies a total cumulative stimulus of $\$ 523.5$ million across all four years in the pre-Games period. This cumulative stimulus is estimated to generate a smaller impact - less than half - on the whole economy.

For employment, on a full-time equivalent (FTE) basis, the construction phase of the Games is estimated to create 887 FTE jobs for Queensland throughout the whole four-year pre-Games period (Table 6). However, this is offset by a reduction of 349 FTEs in ROA, leaving a net effect of just 538 FTEs at the national level.

\section{Games-year (2017-18)}

A short-run closure is applied for the Games year simulation to reflect the brief nature of the Games. There are a few additional assumptions adopted for the macro level as follows:

- We assume the nominal wage rates are fixed in this scenario.

- The short-term nature of the Games will not affect other non-tourism exports across all regions.

- Governments of all states, including Queensland, will not change their spending.

- Road and freight transports in the Gold Coast will improve their productivity by 0.07 per cent and 0.025 per cent, respectively after the completion of Gold Coast Light Rail Stage 2.

- Given the dichotomy between the pre-Games and Games-year periods in the comparative static mode, the build-up of capital from the pre-Games years could not make capital stocks available to demands in the Games-year simulation. This will generate an artificial shortage of capital to industries. 
Table 7 Economic impacts in the Games year - percentage deviation

\begin{tabular}{|c|c|c|c|c|}
\hline & & Queensland & Rest of Australia & Australia \\
\hline & percentage change & & & \\
\hline 1 & Real HH consumption & 0.415 & 0.092 & 0.155 \\
\hline 2 & Real investment & 0.556 & 0.000 & 0.103 \\
\hline 3 & Real GOV consumption & 0.000 & 0.000 & 0.000 \\
\hline 4 & Real exports & 0.474 & 0.010 & 0.073 \\
\hline 5 & Real imports & 0.775 & 0.231 & 0.340 \\
\hline 6 & Real GSP/GDP & 0.160 & 0.032 & 0.056 \\
\hline 7 & Employment & 0.585 & 0.050 & 0.157 \\
\hline 8 & Real wage & -0.174 & 0.041 & -0.002 \\
\hline 9 & Real capital stocks & 0.222 & 0.000 & 0.040 \\
\hline \multirow[t]{2}{*}{10} & Exchange rate & & & 0.545 \\
\hline & Nominal at current prices, $\$ m$ & & & \\
\hline 11 & Gross domestic product & 559 & 476 & 1034 \\
\hline
\end{tabular}

For this reason, capital stocks of selected tourism-related industries are set endogenously to mimic the effect of having capital supply available for use after the construction period (Pham, Xin et al. 2017: 28).

Results in Table 7 indicate a strong increase in employment, and hence income, even though the real wage rates decline marginally. Household consumption is boosted as a consequence. The strong appreciation of the domestic currency (row 10) explains the solid growth of imports (row 5) to facilitate strong demands for investment and household consumption. Imports in Queensland indeed is estimated to have the strongest growth in all regions.

As exports are assumed not to be affected by the Games, the increase in exports (row 4, Table 7) for the state is mainly reflecting the increase in inbound tourism demand by overseas visitors.

The partial treatment of the capital stocks for tourism-related industries in Queensland explains an increase in capital stocks in Queensland in a short-run closure, but not in ROA.

Input requirements for the Games are provided not only by Queensland but also by neighbouring states, particularly New South Wales. These flow-on effects transfer positive stimulus to the ROA region, generating a small increase in employment and real wage rates in ROA. The trade flows generate increased employment across all regions, and as there is no crowding out on exports, the increases in employment in all regions are strong, particularly for Queensland, nearly 0.6 per cent (row 7, Table 7).

Data from the GC2018 Visitor Study indicate a form of the so-called 'spillover effects' that visitors, including domestic and inbound visitors, did not simply stay at the Gold Coast as a single destination. They travelled far and beyond the Gold Coast to maximise their visit to the Games region. It is the pattern of their travelling that stimulates exports in ROA (0.01 per cent, row 4, Table 7). Overall, the net impacts are distributed nearly evenly across Queensland and Rest of Australia.

With respect to employment, it is estimated that the Games generated approximately 12,300 full-time equivalent (FTE) positions in Queensland and just a little 
Table 8 Employment effects of the Games-year (FTEs)

\begin{tabular}{lccc}
\hline & Queensland & Rest of Australia & Australia \\
\hline Games year & 12,298 & 3,902 & 16,200 \\
\hline
\end{tabular}

below 4000 FTEs in ROA (Table 8). Care must be taken in interpreting the FTEs in this Games year and those in the pre-Games period, as the implied time frames of the employment are not the same: it is four years of employment for each FTE in the pre-Games simulation while it is just one year in the Games year period.

\section{Post-Games period (2018-19 to 2021-22)}

The post-Games period is assumed to be four years, not longer than the interval between two consecutive Commonwealth Games. In some similar studies of previous Games, the post-Games period has been assumed to be ten years, but it is more realistic to limit it to the shorter four-year period in which Games effects are more likely to be felt. Given this timespan, it is appropriate to apply a standard long-run closure for this post-Games period without any adjustments, implying that the labour market is subject to a strict constraint at the national level. Growth in employment in Queensland will be offset by changes in employment growth in ROA. Capital stocks are allowed to respond to capital demand to retain the predetermined nationwide rate of return (Table 9).

Data from the ABS indicate that labour productivity growth in the accommodation and food services sector fluctuated in a range of -2.4 per cent to 4.1 per cent over the last four years, with an average improvement of 0.8 per cent per year. Using this historical information, we assume that labour productivity for industries in this group in the Gold Coast and Brisbane will improve marginally above the average at 1.2 per cent, after the experience of the Games year. This improvement is well within the historical range that the industry could attain. Thus we apply this labour productivity gain for the two sectors accommodation and restaurant in the Brisbane and Gold Coast regions.

Government consumption in ROA is no longer required to be constant, as there is no reason for it to be constrained. Government consumption in Queensland, however, is assumed to target the predetermined level of re-prioritisation transfer to ensure budget neutrality for the infrastructure investment. The result for government consumption in Queensland is therefore estimated to decline slightly by 0.167 per cent per year (row 3, Table 9).

The post-Games years are driven strongly by the induced tourism inbound expenditure stimulated by high activity of venue utilisation of Games infrastructure and the induced exports of goods and services. Combined, real exports in Queensland are estimated to increase by nearly 0.4 per cent a year (row 4 , Table 9 ). This is the main factor that drives growth in Queensland in the post-Games period.

Real household consumption increases by 0.15 per cent per year, driven by income generated by the induced exports and venue utilisation, and a modest appreciation of the exchange rate 0.009 per cent (row 10, Table 9). Although the appreciation is small, it facilitates a small increase in imports for Queensland, just a little higher than 0.2 per cent a year, compared with the Games year. As this is a 


\begin{tabular}{|c|c|c|c|c|}
\hline & & Queensland & Rest of Australia & Australia \\
\hline & \multicolumn{4}{|l|}{ Percentage change } \\
\hline 1 & Real HH consumption & 0.155 & 0.058 & 0.077 \\
\hline 2 & Real investment & 0.087 & -0.053 & -0.027 \\
\hline 3 & Real GOV consumption & -0.167 & -0.019 & -0.049 \\
\hline 4 & Real exports & 0.376 & -0.047 & 0.011 \\
\hline 5 & Real imports & 0.217 & 0.071 & 0.101 \\
\hline 6 & Real GSP/GDP & 0.107 & -0.017 & 0.007 \\
\hline 7 & Employment & 0.066 & -0.016 & 0.000 \\
\hline 8 & Real wage & 0.092 & 0.016 & 0.031 \\
\hline 9 & Real capital stocks & 0.063 & -0.044 & -0.024 \\
\hline \multirow[t]{2}{*}{10} & Exchange rate & & & -0.009 \\
\hline & \multicolumn{4}{|c|}{ Cumulative nominal at current prices, \$m } \\
\hline 11 & Gross domestic product & 1431 & -991 & 440 \\
\hline
\end{tabular}

long-run closure, investment is linked to changes in the capital demands, thus it is estimated to increase by 0.087 per cent a year. Queensland as a whole is estimated to increase by 0.1 per cent in its GSP.

For ROA, real exports are estimated to decline by nearly 0.05 per cent per year, adversely driven by the appreciation of the exchange rate as well as the loss of workers to Queensland. The decline in employment in ROA is due to the assumption of full employment at the national level. Increases in employment in Queensland $(0.066$ per cent $)$ is at the expense of a decline in employment in the rest of Australia (-0.16 per cent). The number of jobs on the basis of FTE is presented in Table 10.

Although the real wage rate in ROA is estimated to increase, it is not increasing faster than the decline in the employment, so changes in wage income in the region are estimated to be minimal. Household consumption in ROA is estimated to increase modestly, facilitated mainly by the appreciation of the exchange rate.

At the absolute level, GSP in Queensland is estimated to increase by $\$ 1.4$ billion over the whole four-year post-Games period; however, this increase is offset by a large decline of nearly $\$ 1$ billion in GSP in ROA, leaving a net increase of GDP by only $\$ 440$ million at the national level.

Table 11 provides a summary of stimuli and impacts of the Gold Coast 2018 Commonwealth Games for Queensland and Australia. Stimuli for the pre-Games and post-Games periods are derived by multiplying total stimulus in Tables 2 and 4 by four.

Over the whole nine year period, total stimulus of the Games is estimated to amount to nearly $\$ 3.8$ billion. The effect of the Games on the Queensland economy is estimated to be an increase in its GSP by $\$ 2.5$ billion. Of the total, the contribution of the post-Games period is the most significant - more than 60 per cent of total impacts on the Queensland economy.

However, for the whole Australia, the net impact on gross domestic product (GDP) is only $\$ 1.7$ billion, well below half the total stimulus. This is because the 
Table 10 Employment effects of a typical post-Games year (FTEs)

\begin{tabular}{cccc}
\hline & Queensland & Rest of Australia & Australia \\
\hline Post-games year & 1,320 & $-1,320$ & 0 \\
\hline
\end{tabular}

Table 11 Total impacts of the 2018 Commonwealth Games

\begin{tabular}{lrcr}
\hline & Total stimulus & Queensland & Australia \\
\hline & & (\$million, current prices) & \\
Pre-Games years (2013-14 to 2016-17) & 524 & 494 & 251 \\
Games year (2017-18) & 1,635 & 559 & 1034 \\
Post-Games years (2018-19 to 2021-22) & 1,612 & 1,431 & 440 \\
Total 2013-14 to 2021-22 & 3,771 & 2,484 & 1,726 \\
\hline
\end{tabular}

benefit to Queensland is offset by a larger magnitude of the crowding out effect, devised by CGE mechanism, of resource reallocation from the rest of Australia.

\section{Conclusions}

Impacts of events can be assessed using different modelling techniques, such as CBA, IO and CGE as discussed in this article. For large events, though, it is strongly recommended to use the CGE modelling technique so that both positive and negative effects can be captured explicitly, as has been demonstrated in this article.

The economic impact analysis of the Gold Coast 2018 Commonwealth Games was assessed through three separate periods, from the preparation pre-Games through the operation of the actual Games time, to the post-Games activity that makes use of Games facilities and benefits from improved infrastructure. It is observed that the benefit from the Commonwealth Games does not occur in the Games year only, and definitely not merely in the short twelve-day period of the Games. The flow of benefits started well before the opening ceremony of the Games, and will continue to generate returns in the post-Games period. Among all three periods, it is in the last one that the net benefit to the Queensland economy of the Games will be greatest. Therefore, the role of future venue utilisation and business development is very important in determining the actual economic benefits of the Games.

Overall, the Games were estimated to generate $\$ 2.5$ billion of gross state product in Queensland over nine years after allowing for all costs incurred. The Games stimulate strong growth in household consumption and exports, the main drivers of the event. However, the expansion of the Queensland economy is at the expense of the ROA's economy in the pre-Games and post-Games periods, and more so in the post-Games period.

While the effect on the state GSP can be added across periods, it is conceptually challenging to conclude the effect on employment over time. The nature of these employment numbers is not the same between the short-run and long-run settings, noting that increased employment during the Games year is likely to be relatively short term in nature. 
Care must be taken when comparing the results of this study with previous results, as results of CGE models are determined not only by the magnitude of the shocks but also by parameters in the database, the choice of simulation assumptions and the number of years adopted for the post-Games periods. However, as this article has demonstrated, GCE modelling can provide useful analysis for public policy and decision-making around the economic benefits of hosting such major events as the Gold Coast 2018 Commonwealth Games.

\section{Notes}

1 Maximise utility in micro-economic theory.

2 Brisbane, the Gold Coast and the rest of Queensland are the three regions of Queensland. Queensland and the rest of Australia make up the whole of Australia.

3 Unpublished data applied by Tourism Event Queensland.

4 See https://www.destinationgoldcoast.com/Portals/0/Documents/Corporate/Media/Releases/Games\% 20 gold\%20for\%20business\%20events.pdf.

\section{References}

Australian Bureau of Statistics (ABS) 2018. Labour Force Australia, cat. no. 6202.0. Canberra: ABS.

Barget, E. and Gouguet, J.-J. 2010. 'Hosting mega-sporting events: Which decisionmaking rule?' International Journal of Sport Finance 5: 141-62.

Briassoulis, H. 1991. 'Methodology issues: Tourism input-output analysis'. Annals of Tourism Research 18: 485-95.

Crompton, J. L. 1995. 'Economic impact of sports facilities and events: Eleven sources of misapplication'. Journal of Sport Management 9: 14-35.

DSpark 2018. Commonwealth Games Mobility Intelligence. Unpublished report submitted to Tourism Research Australia.

Dixon, P. B., Parmenter, B. R., Sutton, J. and Vincent, D. P. 1982. ORANI: A multisectoral model of the Australian economy. Contributions to Economic Analysis 142. Amsterdam: North-Holland.

Dwyer, L., Forsyth, P. and Spurr, R. 2004. 'Evaluating tourism's economic effects: New and old approaches'. Tourism Management 25(3): 307-17.

—. (2006). 'Assessing the economic impacts of events: A computable general equilibrium approach'. Journal of Travel Research 45: 59-66.

Giessecke, J. and Madden, J. 2007. The Sydney Olympics, seven years on: An ex-post dynamic CGE assessment. Melbourne: Centre of Policy Studies, Monash University.

Horridge, M., Madden, and J.Wittwer, G. 2005. 'The impact of the 2002-03 drought on Australia'. Journal of Policy Modeling 27(3): 285-308.

Leontief, W. W. 1936. 'Quantitative input and output relations in the economic systems of the United States'. The Review of Economics and Statistics, 18, 105-25.

Li, S., Blake, A. and Cooper, C. 2011. 'Modelling the economic impact of international tourism on the Chinese economy: A CGE analysis of the Beijing 2008 Olympics'. Tourism Economics 17(2): 279-303. doi: 10.5367/te.2011.0025

Madden, J. R. 2002. 'The economic consequences of the Sydney Olympics: The CREA/ Arthur Andersen Study'. Current Issues in Tourism 5(1): 7-21.

Madden, J. 2006. 'Economic and fiscal impacts of mega sporting events: A general equilibrium assessment'. Public Finance and Management 6(3): 346-94. 
Massiani, J. 2018. 'Assessing the economic impact of mega events using computable general equilibrium models: Promises and compromises.' Economic Modelling 75: $1-9$.

Matheson, V. 2009. 'Economic multipliers and mega-event analysis'. International Journal of Sport Finance 4: 63-70.

Meng, S. and Pham, T. 2017. 'The impact of the Australian carbon tax on the tourism industry'. Tourism Economics 23(3): 506-22.

New South Wales Treasury 1997. 'The economic impact of the Sydney Olympic Games: A collaborative study by NSW Treasury and the Centre for Regional Economic Analysis, University of Tasmania'. Hobart and Sydney: University of Tasmania and NSW Treasury.

Office of the Commonwealth Games 2018a. The GC2018 Visitor Study: Gold Coast 2018 Commonwealth Games-Evaluation Report. Brisbane: Office of the Commonwealth Games.

- 2018b. Trade 2018: Gold Coast 2018 Commonwealth Games Trade and Investment Programs- Evaluation Report. Brisbane: Office of the Commonwealth Games.

Pham, T., Jago, L., Spurr, R. and Marshall, J. 2015. 'The Dutch Disease effects on tourism: The case of Australia'. Tourism Management 46: 610-22.

Pham, T. D., Nghiem, S. and Dwyer, L. 2017. 'The economic impacts of a changing visa fee for Chinese tourists to Australia'. Tourism Economics 24(1): 109-26.

Pham, T. D., Simmons, D. G. and Spurr, R. 2010. 'Climate change-induced economic impacts on tourism destinations: The case of Australia'. Journal of Sustainable Tourism 18(3): 449-73.

Pham, T., Xin, J., Naranpanwa, A., Bandaralage, J. and Carmignani, F. 2017. The Economic Impacts of the Gold Coast 2018 Commonwealth Games: A Commissioned Report Submitted to the Office of Commonwealth Games. Brisbane: Queensland Government. Retrieved from https://embracing2018.com/sites/default/files/gc2018-economic-benefits-griffith-uni-report.pdf.

Taks, M., Green, C., Misener, L. and Chalip, L. 2014. 'Evaluating sport development outcomes: The case of a medium-sized international sport event'. European Sport Management Quarterly 3, DOI: 10.1080/16184742.2014.882370. 